\title{
Stress-strain response of high-volume fly ash self-compacting concrete (HVFA-SCC) under uniaxial loading and its effect on the reinforced HVFA-SCC nominal strength
}

\author{
Stefanus Kristiawan ${ }^{1, *}$, Sunarmasto ${ }^{1}$, Agus $S$ Budi $^{1}$, and Desi $C$ Kurniawati ${ }^{2}$ \\ ${ }^{1}$ SMARTCrete Research Group, Civil Engineering Department, Universitas Sebelas Maret, Jl. Ir. \\ Sutami No. 36 A, Surakarta 57126, Indonesia \\ ${ }^{2}$ Civil Engineering Department, Universitas Sebelas Maret, Jl. Ir. Sutami No. 36 A, Surakarta 57126, \\ Indonesia
}

\begin{abstract}
Utilization of High-Volume Fly Ash-Self Compacting Concrete (HVFA-SCC) as a reinforced concrete structural element requires a rational analysis to accommodate the mechanical characteristics of HVFASCC. This study aims to investigate and analyze the mechanical characteristics of HVFA-SCC by examining the experimentally obtained complete stress-strain behavior of this concrete. The results indicate that the compression stress-strain curve of HVFA-SCC is diverse to that of normal concrete (NC) in which the average area under the curve represents $64 \%$ to that of NC. Consequently, the equivalent rectangular compression stress for calculating the nominal flexural strength of reinforced HVFASCC section should be modified by a factor of 0.64 . Based on this theoretical analysis, a close agreement exists between the predicted nominal flexural strength and the experimental result.
\end{abstract}

\section{Introduction}

Reinforced concrete (RC) has been successfully used as a major structural material in the construction of various structures. The structural performance of RC is controlled by the composite action of concrete and the embedded reinforcements. The efficacy of the action is further influenced by the mechanical behavior of the concrete and reinforcements. From a designer's point of view, there is a window of opportunity to select a proper concrete material in combination with reinforcements in order to obtain a reliable structural performance of RC for a particular case. The flexibility of the design could also be helpful in anticipating future issues and demands.

Nowadays, sustainability has become the main issue in the development of various infrastructures. For concrete industries, this may be achieved by optimizing the mix design, improving the durability of the concrete, using materials with less impact to the environment, etc. The optimization of mix design would promote a concrete with a higher

* Corresponding author: s.a.kristiawan@ft.uns.ac.id 
performance, with minimal resource consumption required for its production. The durability of concrete is another crucial aspect to ensure a longer service life of the structures with minimum maintenance throughout the life of the structure. In addition to the specification of the concrete mixture, concreting practices should also be taken into consideration as they influence the quality of the constructed concrete. This is especially true for concrete manufactured on-site where the control of the production may be hampered by the lack of skilled workers. As a result, many new concrete structures already show a sign of decay (e.g. honeycomb) which impairs its durability. A solution has been found by Ozawa and Okamura [1] for this case with the use of self-compacting concrete (SCC).

SCC is a special type of concrete with the ability to flow and fill any recess within a formwork under its own weight without any aid of vibrations. The ingredients for making SCC are basically similar to those for making conventional concrete. The main difference is in its proportion. The key factors to obtain the flowability of concrete is a moderate viscosity. To achieve this property, the amount of fine ingredients (with a maximum diameter of $0.125 \mathrm{~mm}$ ) and the use of superplasticizer are essential. The amount of fine ingredients in SCC is higher whereas the coarse aggregate is lesser than the corresponding amount of those ingredients in conventional concrete [1]. The requirement of a high amount of fine ingredients could lead to a high demand of the cement content. It is common to obtain flowable concrete using relatively high cement content [2]. In terms of sustainability, the use of a high cement content is undesirable.

Many mineral admixtures have been used to partially substitute cement in the production of concrete. Naturally, the preferred use of these materials will be determined by the availability of these materials in that particular location. Fly ash is abundantly available as one of the coal combustion products of coal-fired power plants. An inclusion of fly ash as partial cement substitution in SCC has been widely investigated. It has been shown that a very high inclusion of fly ash, up to a $70 \%$ replacement level, is possible. However, previous works mainly focus on investigating the material properties of SCC incorporating high volume fly ash [3-8]. For successful utilization of SCC incorporating high volumes of fly ash as structural element, there is a need to further identify the mechanical behavior of this concrete as a basis to develop an analysis on its structural behavior.

In terms of the flexural behavior of the RC beam element, the nominal strength of the beam made from conventional concrete is analyzed based on several assumptions: below the neutral axis concrete is considered in a state of cracks and the tensile stresses of the beam is fully carried by the tensile reinforcements. The concrete compression stresses are proportionally linear up to 0.5 of its compressive strength $\left(f^{\prime} c\right)$ as distance from the neutral axis; beyond this value they are no longer proportional. This behavior is represented by the non-linear compression stresses diagram in Figure 1.b. The curved compression diagram is replaced with a rectangular one with a constant stress of $0.85 f^{\prime} c$ as shown in Figure 1.c. The rectangular diagram of depth $a$ (Figure 1.c) is assumed to have the same center of gravity and total magnitude as the curved diagram. This distance $a$ is set equal to $\beta_{l} c$, where $\beta_{l}$ is a value determined by testing and specified by the code. These assumptions will be used to calculate the theoretical or nominal flexural strength of RC beams [9].

The equality of the curved compression diagram of Figure 1.b and the rectangular diagram of Figure 1.c may not applicable for non-conventional concrete. This is especially the case if the compression stress-strain diagram of the particular concrete shows different behavior. Accordingly, the analysis of the flexural strength of beams made from nonconventional concrete should be developed on the basis of the unique compression stressstrain diagram of that concrete. This paper aims to present the compression stress-strain diagram of SCC incorporating high volume fly ash, and compared the behavior with that of conventional concrete. Subsequently, an analysis of the nominal flexural strength of RC 
beam with SCC incorporating high volume fly ash is proposed and verified with the experimental results.

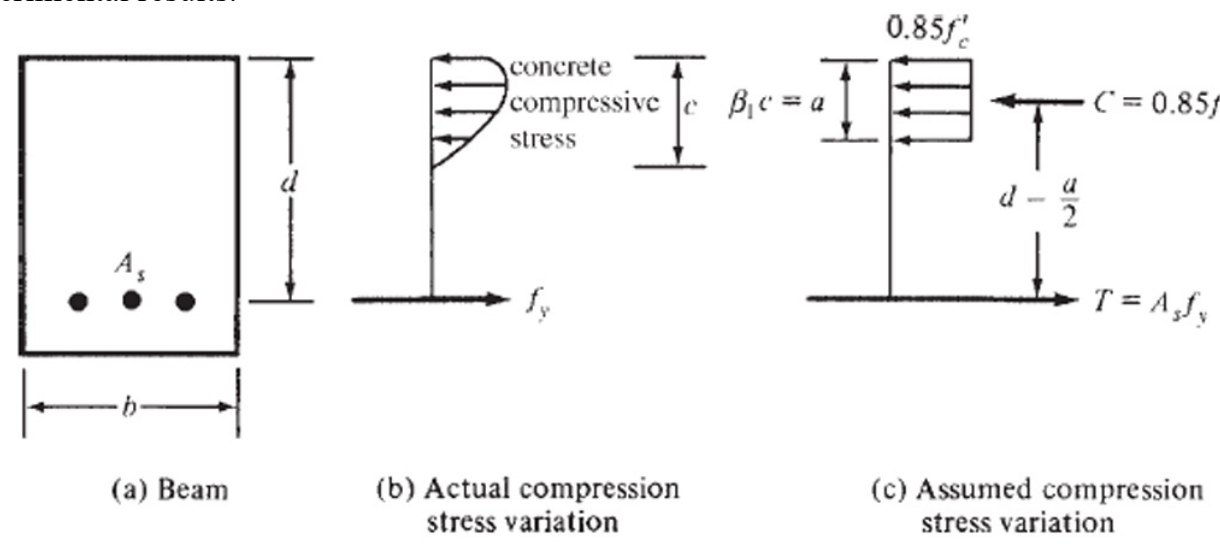

Fig. 1. Compression and tension couple at nominal moment [9].

\section{Materials and testing}

\subsection{Materials}

The proportion of SCC incorporating high volume fly ash (HVFA-SCC) investigated in this study is presented in Table 1. An inclusion of fly ash in the mixture was set at $60 \%$ by the weight of the total binder (cement plus fly ash). The mixture of HVFA-SCC gave a slump flow of about $700 \mathrm{~mm}$ (Figure 2). The chemical composition of fly ash is given in Table 2. A conventional concrete mixture (NC) was also prepared for the purpose of comparing the compression stress-strain behavior to that of HVFA-SCC. The coarse and fine aggregate properties for making both types of concrete are shown in Table 3.

Table 1. The proportion of concrete mixtures $(\mathrm{kg})$ as per $1 \mathrm{~m}^{3}$.

\begin{tabular}{|c|c|c|c|c|c|c|}
\hline Specimen ID & Cement & $\begin{array}{c}\text { Fly } \\
\text { ash }\end{array}$ & $\begin{array}{c}\text { Coarse } \\
\text { Aggregate }\end{array}$ & $\begin{array}{c}\text { Fine } \\
\text { Aggregate }\end{array}$ & Water & Superplasticizer \\
\hline HVFA-SCC & 294 & 442 & 703 & 578 & 211 & 7.3 \\
\hline NC & 388 & - & 942 & 771 & 225 & - \\
\hline
\end{tabular}

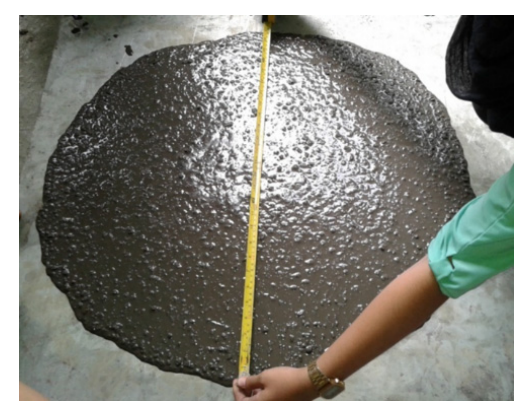

Fig. 2. Slump flow of HVFA-SCC. 
Table 2. Chemical composition of fly ash (in \%).

\begin{tabular}{|c|c|c|c|c|c|c|c|c|c|c|}
\hline $\mathrm{SiO}_{2}$ & $\mathrm{Al}_{2} \mathrm{O}_{3}$ & $\mathrm{Fe}_{2} \mathrm{O}_{3}$ & $\mathrm{TiO}_{2}$ & $\mathbf{C a O}$ & $\mathbf{M g O}$ & $\mathrm{K}_{2} \mathrm{O}$ & $\mathrm{Na}_{2} \mathrm{O}$ & $\mathbf{P}_{2} \mathrm{O}_{5}$ & $\mathbf{S O}_{3}$ & $\mathrm{MnO}_{2}$ \\
\hline 45.27 & 20.07 & 10.59 & 0.82 & 13.32 & 2.83 & 1.59 & 0.98 & 0.41 & 1 & 0.07 \\
\hline
\end{tabular}

Table 3. Properties of aggregates.

\begin{tabular}{|c|c|c|c|}
\hline Aggregate & Absorption & $\begin{array}{c}\text { Bulk specific gravity } \\
\text { (SSD) }\end{array}$ & $\begin{array}{c}\text { Fineness } \\
\text { modulus }\end{array}$ \\
\hline Fine & $1 \%$ & 2.66 & 2.98 \\
\hline Coarse & $5.3 \%$ & 2.51 & 5.69 \\
\hline
\end{tabular}

\subsection{Specimens}

Cylinders of $7.5 \times 150 \mathrm{~mm}$ were prepared for measurements of the mechanical behaviors of the concretes under axial loading. Each type of concrete was represented by two cylinders. Other cylinders of 150x300 mm were also prepared for measurements of the compressive strengths. Three cylinders were made for determining the average compressive strengths of the respective concrete. The flexural strength of $\mathrm{RC}$ concretes was tested on beam specimens having a size of $60 \times 100 \times 1300 \mathrm{~mm}$. The flexural and shear reinforcements are shown in Figure 3. The flexural reinforcements have a diameter of $10 \mathrm{~mm}$ (D10) while the shear reinforcements were $6 \mathrm{~mm}$ (D6). The yield stress of the reinforcements was $353 \mathrm{MPa}$ and $326 \mathrm{MPa}$ for D10 and D6, respectively. The amount of reinforcements has been designed to ensure flexural failure mode.

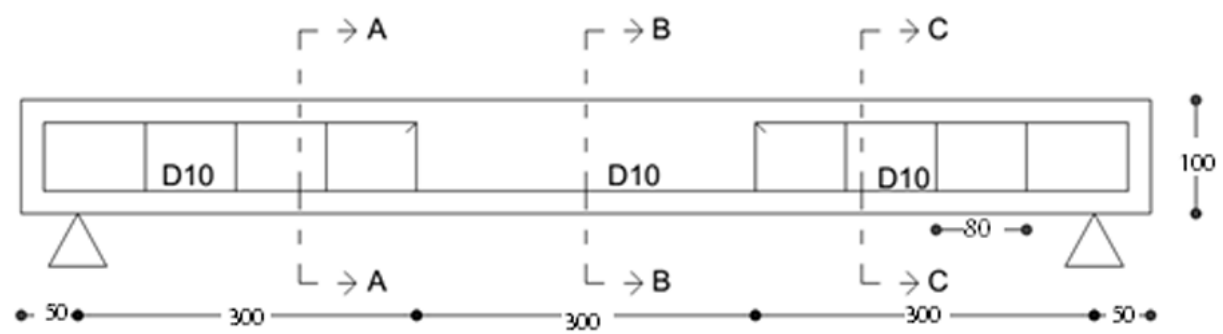

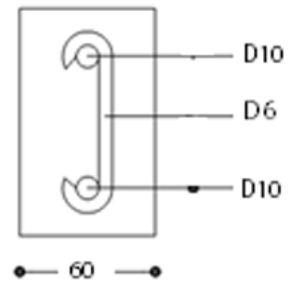

$\mathrm{A}-\mathrm{A}$

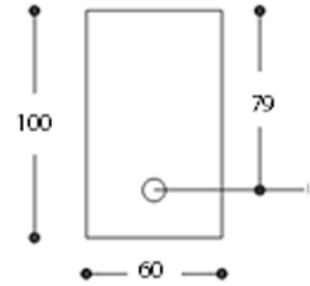

B-B

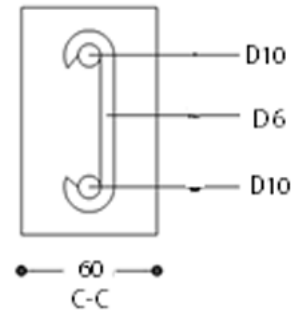

Fig. 3. Flexural RC beam specimen.

\subsection{Testing}

The compressive strength and mechanical behavior of the concretes under axial loading were tested using a Universal Testing Machine (UTM). Meanwhile, four points of loading were carried out to determine the flexural behavior of the RC beams. Originally, both the shear and flexural span were proposed at $300 \mathrm{~mm}$. However, it was desired to provide a 
longer flexural span in order to observe the behavior of the cracking propagation in the flexural span in more detail. Hence, a shear and flexural span of $150 \mathrm{~mm}$ and $600 \mathrm{~mm}$ respectively was employed. Theoretically, the beams are still stronger in shear than in flexure even though they are loaded at these spans. Figure 4 shows the loading of the RC beam for determining the flexural strength. The load and mid-span deflection were continuously recorded until failure.

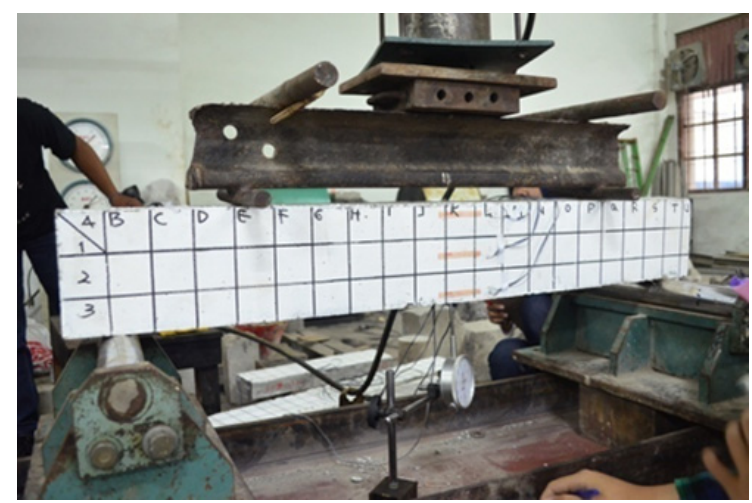

Fig. 4. Flexural strength test of RC beam.

\section{Results and discussion}

\subsection{Mechanical properties}

The average 28-day compressive strength of the NC and HVFA-SCC is $27.5 \mathrm{MPa}$ and $52.84 \mathrm{MPa}$, respectively. The compression stress-strain behavior of those concretes is presented in Figure 5. The difference of actual stress-strain diagrams between the NC and HVFA-SCC can be observed in Figure 5.a. The HVFA-SCC tends to show a steeper curve either at the ascending or descending brand. The peak strain $\left(\varepsilon_{\mathrm{p}}\right)$ of the HVFA-SCC curves is in the range of 0.0014-0.0016 while the corresponding range for the NC is 0.00110.0018 . The ultimate strains of both concretes are bounded between $0.0017-0.0022$. In the analytical prediction of the nominal flexural strength, a value of ultimate strain at 0.002 is assumed. Comparing the result and the assumed value of the ultimate strain, it is satisfactory to use an ultimate strain of 0.002 in the analytical calculation of the nominal flexural strength.

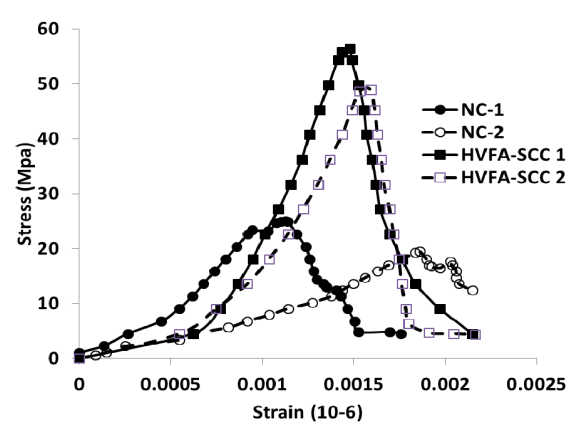

a. Actual stress-strain values

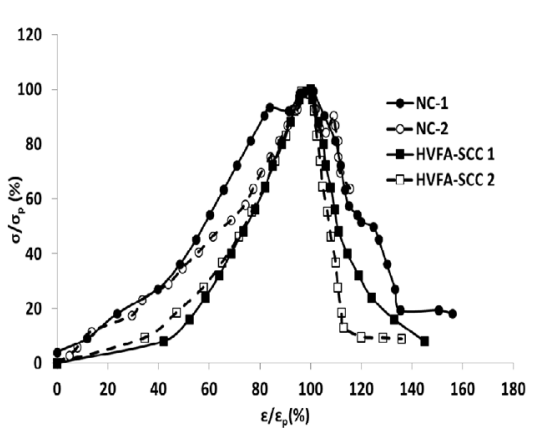

b. Normalized stress-strain values

Fig. 5. Compression stress-strain behavior of NC and HVFA-SCC. 
It is also adequate to assume strain compatibility conditions when calculating nominal flexural strength; the strain is linearly proportional as the distance from the neutral axis. Based on this assumption, the compression stress diagram of Figure 1.b can be obtained either theoretically or experimentally. For the NC, a theoretical assumption has been made as previously mentioned in the introduction. For the HVFA-SCC which shows a different behavior of compression stress-strain relationship, it is required to modify the theoretical assumption of the equality between the actual compression stress diagram (Figure 1.b) with the equivalent rectangular compression stress diagram (Figure 1.c). For this purpose, the area under the stress-strain diagrams between the two concretes is compared. The comparison should be made on the normalized stress-strain diagram as presented in Figure 5.b. The normalized stress and strain is defined as the ratio between stress $(\sigma)$ and its peak stress $\left(\sigma_{\mathrm{p}}\right)$ and the strain $(\varepsilon)$ and its peak strain $\left(\varepsilon_{\mathrm{p}}\right)$, respectively. It is found that the average area under the normalized stress-strain curves of HVFA-SCC is about $64 \%$ of the corresponding NC. Hence, this value will be used to modify the equivalent rectangular compression diagram of Figure 1.c for calculating the nominal flexural strength of HVFASCC.

\subsection{Flexural behavior of reinforced HVFA-SCC beam}

The typical load-deflection behavior of reinforced HVFA-SCC beams under flexural loading is presented in Figure 6. Initially, the load and deflection are linearly proportional. Visual observation detects that the beams start to crack when the load is about 0.73 tons. After this initial crack occurs, an increase of load triggers a formation of new cracks. As a result, the rigidity of the beams is reduced with a consequence of slightly higher increments of deflection. The reinforcements begin to yield when the load reaches 1.52-1.66 tons. The post yield behavior is characterized by a higher increment of deflection at a small increase of load. Finally, the beams fail at an ultimate load of about 2.5 tons. The whole behavior of the beams is characterized by the following cracks formation and propagation (Figure 6).

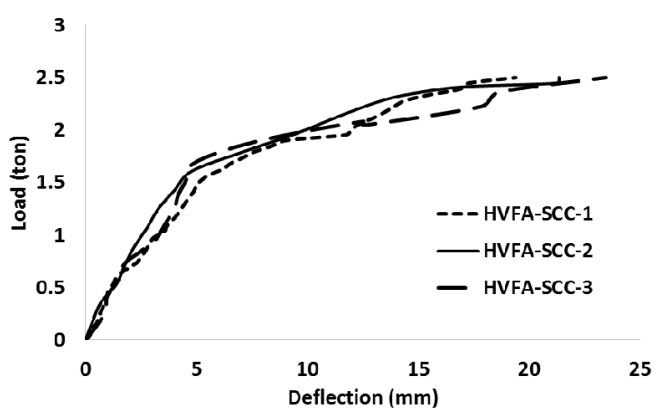

Fig. 6. Load-deflection behavior of reinforced HVFA-SCC beams under flexure. 


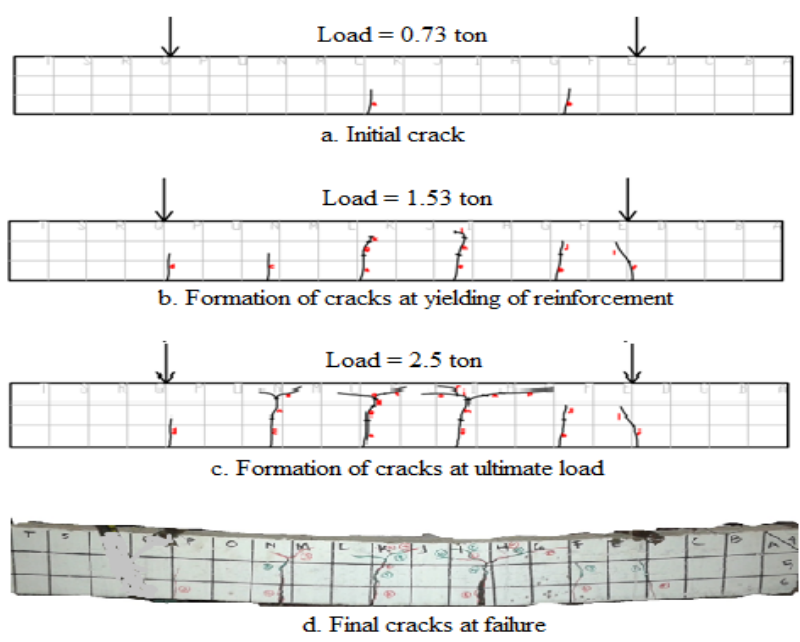

Fig. 7. Formation and propagation of cracks.

\subsection{Theoretical nominal flexural strength of reinforced HVFA-SCC}

In the previous section, it has been shown that the compression stress-strain behavior of HVFA-SCC is different to that of NC. It is also suggested that a value of 0.64 may be used to modify the equivalent rectangular compression stress diagram of HVFA-SCC. The nominal flexural strength of a reinforced HVFA-SCC beam section could be computed using a similar formula as that of $\mathrm{NC}$ beams (see Figure 1):

$$
M_{n}=A_{s} f_{y}\left(d-\frac{a}{2}\right)
$$

where $a$ and $d$ can be obtained from the equilibrium of the compression force $(C)$ of concrete and the tension force $(T)$ of the reinforcement. However, for HVFA-SCC the value of $C$ should be modified as follows:

$$
C=\left(0.85 f_{c}^{\prime} 0.64 a b\right)
$$

to account for a lower area under the stress-strain diagram. Equation 2 implies that the rectangular diagram of Figure 1.c is assumed to have a depth of $0.64 a$ in order to give a comparable area to the area under the stress-strain diagram of the HVFA-SCC. Using the above formulas, the nominal flexural strength of the HVFA-SCC beam investigated in this study equals $1.78 \times 10^{6}$ N.mm. Given the loading span, this nominal flexural strength is equivalent to a load of 2.37 tons which is close to the ultimate load determined experimentally.

\section{Conclusions}

The compression stress-strain curve of HVFA-SCC is different to that of NC in which the average area under the curve represents $64 \%$ to that of $\mathrm{NC}$. Consequently, the equivalent rectangular compression stress for calculating the nominal flexural strength of a reinforced HVFA-SCC section should be modified by a factor of 0.64 . Based on this theoretical analysis, close agreement exists between the predicted nominal flexural strength and the experimental result. 
The authors would like to thank the Universitas Sebelas Maret for providing financial support under the Mandatory Research Scheme that made this research possible (Contract No. 623/UN27.21/PP/2017).

\section{References}

1. H. Okamura, K. Ozawa, Concr. Lib. JSCE. 25, 107-120, (1995)

2. P. Dinakar, Mag. Concr. Res. 64, 401-409, (2012)

3. J. Khatib, Constr. Build. Mater. 22, 1963-1971, (2008)

4. S.A. Kristiawan, M.T.M. Aditya, Proc. Eng. 125, 705-712, (2015)

5. S.A. Kristiawan, Wibowo., S. As'ad, B.S. Gan, D.P. Sitompul, Advances in Civil, Architectural, Structural and Constructional Engineering, 31-35

6. S.A. Kristiawan, Sunarmasto, G.P. Tyas, IOP Conf. Ser.: Mater. Sci. Eng. 107, 012029

7. R. Siddique, Mater. Des. 32, 1501-1507, (2011)

8. Sunarmasto, S.A. Kristiawan, Appl. Mech. Mater. 754-755, 447-451, (2015)

9. J.C. McCormac, R.H. Brown, Design of reinforced concrete (Ninth Edition) (John Wiley \& Sons, Inc., 111 River Street, Hoboken, NJ), (2014) 